\title{
DO INDESEJÁVEL AO INEVITÁVEL: A EXPERIÊNCIA VIVIDA DO ESTIGMA DE ENVELHECER NA CONTEMPORANEIDADE ${ }^{1}$
}

\section{Virgínia Moreira e \\ Fernanda Nícia Nunes Nogueira}

Resumo: Este artigo discute o processo de envelhecimento na contemporaneidade ocidental a partir de uma pesquisa fenomenológica realizada com sujeitos colaboradores que se encontram na fase da maturidade.Os resultados apontam para a compreensão do envelhecimento como uma experiência ambígua e também estigmatizada, na medida em que se traduz na identificação com um estereótipo negativo e com a recusa de ser portador de uma marca que inferioriza ou exclui: ser velho. Envelhecer num cenário marcado pelo culto à juventude e à beleza, que impõe um padrão estético como ideal a ser conquistado por todos, transforma essa experiência, que é um fenômeno biológico "inevitável", em um fenômeno cultural da ordem do "indesejável".

Palavras-chave: Envelhecimento. Estigma. Fenomenologia.

Vivemos a "era do envelhecimento", período que vai de 1975 a 2025 (Costa, 1998). Em 2000, segundo estimativas da Organização Mundial da Saúde (OMS, www. who.int/hpr/ageing), o planeta tinha 600 milhões de idosos com 60 anos de idade ou mais. Em 2025, estima-se que serão 1,2 bilhões de idosos, sendo que dois terços estarão vivendo em países em desenvolvimento. Na contemporaneidade, o envelhecimento humano passou a ser considerado um importante fenômeno social, devido sobretudo ao aumento da expectativa de vida da população e à redução da taxa de

1 Artigo elaborado a partir da dissertação de mestrado defendida por Fernanda Nícia Nogueira sob orientação da Profa. Dra. Virginia Moreira no Programa de Mestrado em Psicologia na Universidade de Fortaleza - UNIFOR. 
natalidade. Essa questão é fundamental face às repercussões nas diferentes esferas da estrutura social, econômica, política e cultural das sociedades do século XXI, tornando o envelhecer um campo privilegiado de investigação, que vem chamando a atenção de pesquisadores nas mais diversas áreas.

O Brasil, antes referido como um país de jovens, também vem fazendo sua transição demográfica e passa por um rápido processo de envelhecimento populacional, fato atribuído aos dois fatores já apontados: aumento da expectativa de vida e redução da natalidade. Prevê-se que em 2020, dos 1,2 bilhões de idosos no mundo, 34 milhões de brasileiros estarão acima de 60 anos, o que corresponderá à sexta população mais velha do planeta (Minayo \& Coimbra Jr., 2002).

O envelhecimento populacional se dá no bojo de profundas transformações econômicas sociais, políticas, ideológicas e científicas. Viver e envelhecer nesse cenário de instabilidade, marcado por mudanças velozes do conhecimento e dos valores culturais, caracterizado pelo fenômeno da globalização e pelo consumismo de que decorre a rápida obsolescência de objetos, pessoas e relações, é uma experiência geradora de insegurança e mal-estar para o sujeito contemporâneo.

A prática clínica psicoterápica permite constatar o quão difícil é, para a maioria das pessoas, aceitar o curso natural do envelhecimento. Para muitos pacientes, os sinais de amadurecimento são vivenciados com muita aflição, tornando as pessoas bastante vulneráveis [ao medo de envelhecer]. Constata-se também um intenso movimento no sentido de adiar ou tentar evitar esse processo por meio de iniciativas que objetivam a manutenção de uma aparência jovial.

A pesquisa que originou este artigo buscou a compreensão da experiência subjetiva no processo de envelhecimento, compreendido em sua mútua constituição ${ }^{2} \mathrm{com}$ a realidade sócio-cultural. Como se dá a experiência de envelhecer na sociedade ocidental contemporânea? O que o sujeito contemporâneo experiencia diante dos naturais e inevitáveis sinais de mudança no corpo e de uma forma de vida que se transforma? Como se vive o envelhecer numa sociedade caracterizada pelo primado estético, que cultua valores como a beleza do corpo, a produtividade, o dinamismo, a força, o novo e o mito da juventude eterna? O que dizer dos efeitos dessa vivência para as subjetividades?

\section{A contemporaneidade e o envelhecimento}

Pensar a experiência contemporânea do envelhecimento implica, seguramente, a consideração do entrelaçamento do entorno sócio-cultural

2 O conceito de mútua constituição é definido por Coelho Júnior (1988) como a reciprocidade ou a reversibilidade entre sujeito e objeto, ou corpo e mundo, ou mundo e homem, em que não se pode demarcar o limite do que é próprio de cada um. 
em que essa experiência se dá com suas determinações históricas. Nesse contexto, inúmeras são as ocorrências [sociais, culturais, políticas e econômicas] que influenciam o estilo de vida, os valores e padrões sociais e, conseqüentemente, os modos de ser do homem e as estruturas psíquicas que se produzem. Incerteza, turbulência, mudanças contínuas, explosão tecnológica, globalização constituem a atualidade e exigem novas e rápidas respostas nos planos individual e coletivo.

Compreender isso tem sido um desafio para pesquisadores de diversas áreas, sendo evidente a divergência entre os vários teóricos sobre os significados da pós-modernidade ou da contemporaneidade. Para Featherstone (1995), o que se chama pós-modernidade não é simplesmente uma formulação teórica, mas algo impulsionado também por movimentos artísticos e culturais que referenciam as mudanças que vivenciamos na atualidade. Segundo esse autor, os termos pós-modernidade, pós-modernismo, pós-moderno e seus derivados foram usados pela primeira vez por Federico de Onis, na década de 1930, mas tomaram vulto na década de 60, no meio artístico de Nova lorque, avançando nos campos da arquitetura, da música, da literatura e também nas ciências humanas.

O termo pós-modernidade e suas variações contemplam a qualificação de um determinado presente e evidenciam as mudanças que estão acontecendo na cultura contemporânea. Todos os esforços teóricos parecem representar a necessidade de expressar a condição de profunda complexidade das sociedades fundadas nesta etapa do capitalismo, que comporta um novo conjunto de valores e uma pluralidade de sentidos geradora de mudanças na ordem social. Explicita, com isso, o caráter mutável e instável da atualidade, diferenciando-se da modernidade, período da história ocidental que emergiu na Europa após o Renascimento e foi consolidado no século XVIII, quando se construiu a expectativa de um mundo mais heterogêneo em relação às sociedades medievais.

Assim, a pós-modernidade ou a contemporaneidade pode ser definida a partir de vários enfoques, mas sempre terá como característica a emergência de uma cultura midiática em que o cenário social funda-se num forte apelo ao consumo, estimulado pelos meios de comunicação de massa, os quais contribuíram decisivamente para tornar a imagem soberana, marcando a sociedade pelo fenômeno da "estetização da vida cotidiana" (Feathersthone, 1995). A beleza, a juventude, a felicidade, o corpo perfeito e o sucesso pessoal constituem bens ou mercadorias que se pode adquirir.

Nessa conjuntura, a dimensão estética torna-se um valor fundamental, consolidando-se a importância que a imagem e a aparência passam a desempenhar, fortalecendo-se a tendência ao narcisismo. Maia e Albuquerque (2000) trazem à discussão a cultura da imagem predominante nas sociedades contemporâneas, nas quais o instantâneo e a busca pelo prazer imediato são valores essenciais. Chamam atenção para os mecanismos "imagéticos midiáticos" como modeladores da subjetividade e destacam 
a relevância desse processo no crescimento das patologias narcísicas na prática clínica atual. O narcisismo é reforçado pela cultura de consumo que se fundamenta na valorização de uma imagem ideal, a qual, para ser alcançada, demanda investimentos de tempo e dinheiro voltados ao corpo.

Birman (1999) caracteriza a sociedade pós-moderna pelas formulações de cultura do narcisismo, visão adotada pelo norte-americano Lasch, e de sociedade do espetáculo, leitura do francês Debord. Segundo a visão de Lasch, o mundo estaria centrado na individualidade e o que importa é a exaltação gloriosa do próprio eu, com o sujeito buscando a estetização de si mesmo, transformada no propósito de sua existência. Na interpretação de Debord, a exigência do espetáculo é o que move as relações sociais, e o cuidado excessivo com o próprio eu se transforma em admiração do sujeito e dos outros. A exibição se transforma na finalidade da existência [do sujeito].

Estudos sobre o envelhecimento em diferentes culturas são utilizados para demonstrar diferentes experiências de envelhecer (Adler, 1999; Uchôa, 2003) e questionam a universalidade da visão ocidental que representa a velhice com as idéias de deterioração e perdas. Esses estudos também contribuíram para ver a velhice e o envelhecimento não só como fenômenos biológicos e naturais, mas como fenômenos profundamente influenciados pela cultura. Em certas sociedades, em especial as orientais, 0 envelhecimento é compreendido mais em termos de aquisição e progresso, e os idosos são respeitados pelos conhecimentos que adquiriram ao longo da vida e pelos ensinamentos que podem dar aos mais jovens.

Beauvoir (1990), ao estudar diversos grupos de sociedades primitivas, verificou quão variadas são as elaborações culturais referentes ao envelhecimento, e sua obra ressalta o quanto esse processo, naturalmente da ordem do biológico, é representado cultural e socialmente, ressaltando a forma como as sociedades ocidentais historicamente lidam com o fenômeno.

Marcadamente individualistas, narcísicas, exibicionistas e pouco solidárias, nessas sociedades o envelhecimento é investido de valores negativos, tornando o velho, a velhice e o envelhecer algo indesejável e gerador de sofrimento. Enquanto a juventude é fortemente exaltada, a velhice é excluída e estigmatizada, basta ver que, numa sociedade capitalista, o velho perde seu poder como produtor de bens e riquezas e como consumidor e, conseqüentemente, perde seu valor social. A velhice e o envelhecimento situam-se na contracorrente de uma sociedade centrada na produção, no rendimento e no dinamismo. No engendramento dessa exclusão está um sistema político e econômico que prioriza a força jovem no mercado de trabalho, descartando aqueles considerados "velhos ou ultrapassados".

Ainda marcando o cenário contemporâneo, registram-se os avanços da ciência e todas as valiosas conquistas obtidas na produção de conhecimento e de tecnologia que visam ao prolongamento da vida humana e à ampliação [das fronteiras] da longevidade, reforçando a ilusão da juventu- 
de eterna.Todo esse progresso possibilitou aumentar a expectativa de vida e promover a manutenção do vigor físico, da beleza e da saúde, configurando-se um contexto resistente ao envelhecimento.

Como o envelhecimento é evidenciado de uma forma antagônica ao padrão estético imposto, ele passa a ser vivido como um defeito que precisa ser disfarçado por meio de múltiplas técnicas que prometem o rejuvenescimento. Preconiza-se o "desejável" (manter-se com um corpo jovem, belo e perfeito), que é vendido como antídoto ou remédio do "inevitável" (o envelhecer), que, além da experiência existencial de confronto com a finitude de que se reveste, passa a ter um peso adicional de caráter cultural. Esse impasse entre o "desejável" e o "inevitável" evidencia a forma como as forças sócio-culturais podem reduzir a possibilidade de vivências significativas [e ricas] na construção da subjetividade. A ciência e a tecnologia parecem estar a serviço de uma sociedade que reafirma desejos de viver eternamente a juventude e de afastar a morte. Intervindo tecnologicamente no corpo para alterar suas formas, também se interfere simbolicamente no indivíduo, modificando suas representações e sua subjetividade.

A contemporaneidade produz assim um grande paradoxo. Por um lado, é exitosa nos esforços da ciência para aumentar a expectativa de vida, por outro lado, não está preparada para acolher e definir o lugar e o papel dos que envelhecem. É como se a velhice fosse prolongada, mas não se quisesse saber dela. No contexto sócio-cultural da atualidade ocidental, não há um lugar nem um significado próprio que valorize a maturidade e a experiência vivida. Os valores, as atitudes e as práticas são de exclusão, negação ou marginalização - processos de estigmatização - dos que têm a longevidade ampliada (Gusmão, 2001; Zuben, 2001).

No bojo de tais transformações, existe também um movimento para desconstruir a identidade de velhos de outras gerações e reconstruí-la sob a forma de uma velhice autônoma, ativa e bem-sucedida. Com suportes médicos, tecnológicos e mercadológicos, induz-se o surgimento de "uma nova velhice", experienciada por homens e mulheres que ganham mais tempo de vida, primam por uma aparência mais jovem, adotam novos valores e revelam comportamentos identificados com o de gerações mais novas. A pressão sócio-cultural atua na negação da velhice tradicional, estimulando aqueles que combatem o envelhecer quer fisicamente, quer psicologicamente ou socialmente. O envelhecer no século XXI torna-se uma experiência profundamente diferente do que foi até aqui.

Mercadante (2003) refere-se à existência de um modelo [social] ideológico de velho, presente no imaginário social, que é construído em oposição à identidade de jovem. Em seus estudos com idosos, pessoas com mais de 60 anos, esse modelo serve para incluir "outros" idosos, e não cada indivíduo em particular, constatando que existe uma fuga pessoal, negadora da visão [ideológica] de velho, que abre possibilidade para criar uma nova forma pessoal de sê-lo. 
Debert (2002) destaca que, na mídia brasileira, coexistem anúncios que reforçam a imagem de uma velhice dependente, retrógrada, com uma outra que realça prestígio, poder e participação, percebendo uma tendência cada vez maior de representar o velho de forma não tradicional, isto é, mais positivamente. Esse fato propicia que a velhice se torne uma questão de escolha pessoal e de distinção entre os indivíduos que se deixam envelhecer e aqueles que reagem ativamente e rejeitam o envelhecimento. A juventude transforma-se em um valor a ser conquistado e um bem a ser adquirido, enquanto a velhice torna-se uma questão de negligência, de indivíduos que se entregaram, que não se envolveram em atividades motivadoras e não consumiram produtos e serviços que combatem o envelhecimento. Envelhecer vira sinônimo de descuido diante de tantos recursos disponíveis para se combater o envelhecimento. Em uma sociedade desigual, esse mecanismo reforça cada vez mais a injustiça social.

O envelhecimento passa, ideologicamente, a ser posto como uma questão individual, isto é, desloca-se para o sujeito toda a responsabilidade pelos problemas que possa estar enfrentando no seu envelhecer e que, na realidade, são questões de caráter político, social e econômico (Debert, 2004; Motta, 2000) em uma sociedade que não se rende ao "inevitável"e se alimenta de vender o "desejável."

A experiência de envelhecimento tende a ser vista como uma opção individual, um estilo de vida frente a um leque variado de produtos e serviços, e não mais como uma vivência inevitável do passar dos anos. Envelhecer constitui-se em uma luta contra a própria velhice, que culmina na adoção de práticas maníacas que dão a sensação de restaurar a juventude perdida, na busca incessante por impedir o"inevitável".

\section{O envelhecer como uma experiência estigmatizada}

O processo de envelhecimento humano é complexo e requer a participação de diversas disciplinas para uma abordagem de múltiplos contornos $^{3}$. Trata-se de um fenômeno que apresenta características diferentes de acordo com a cultura, com o tempo e com o espaço e perpassa trajetórias da vida individual, social e cultural. Nesse sentido, o processo de envelhecimento vai além das mudanças bio-psico-sociais, tendo suas especificidades marcadas pela posição de classe social, pela cultura, pelas condições sócio-econômicas e sanitárias do indivíduo ou da comunidade.

Trata-se de um fenômeno universal, um processo de mudanças intrínsecas ao desenvolvimento humano, mas heterogêneo, pois cada pessoa, como ser único, experiencia e desenvolve singularmente seu próprio processo de envelhecimento (Neri, 2001).

3 O conceito de múltiplos contornos foi originalmente utilizado por Merleau-Ponty (1966/1980) para descrever a pintura de Cézanne, sendo utilizado posteriormente na psicopatologia como uma lente fenomenológica crítica por Moreira $(2002,2004,2005,2007)$. 
A vivência do processo de envelhecimento, que deveria ser natural, na medida em que é vivida de maneira estigmatizada, passa a representar uma ameaça à auto-estima, à aceitação de si, tornando as pessoas vulneráveis a sofrimentos psíquicos de toda ordem e até mesmo a patologias.

A noção de estigma surgiu com o estudo pioneiro de Goffman (1998), que define o indivíduo estigmatizado como aquele que tem uma característica diferente da que a sociedade prevê. Goffman procura esclarecer a relação do estigma com a questão do desvio, visto que a sociedade estabelece os meios de categorizar as pessoas, definindo os atributos comuns e naturais para cada uma dessas categorias. Baseando-se nessas pré-concepções, estabelecem-se expectativas e exigências que se apresentam de modo rigoroso às pessoas. Para esse autor, os estigmatizados são indivíduos com deformações físicas, psíquicas ou de caráter, ou com qualquer outra característica que os tornem, aos olhos dos outros, diferentes, inferiores, e estes, então, lutam diária e constantemente para fortalecer e até construir uma identidade social. Têm uma característica diferente da que estava prevista, enquanto os "normais" são os que não se afastam [negativamente] das expectativas particulares definidas. Como resposta destes aos estigmatizados, encontram-se discriminações, preconceitos, ideologias que pretendem explicar a inferioridade e o perigo que ela representa, bem como a utilização de termos depreciativos para referir o estigma, tais como aleijado, bastardo, retardado, velho etc.

O estigma da idade insere-se em uma lista de estigmas potenciais que reflete padrões e regras abertas às mudanças da história e da cultura, e a idéia de estigma não reside apenas em uma marca individual, pois também é culturalmente determinada na medida em que reflete os valores, padrões e normas do sistema social (Lewis, 1998).

Goldfarb (1998) refere-se a Butler como criador do neologismo ageism e a Salvarezza, como autor do equivalente viejismo, ambos os termos utilizados para referir o tratamento preconceituoso e estigmatizante dado aos idosos e à velhice. Tompson e Tompson (1999) apontam para o ageism, assim como para o sexismo e o racismo, como formas de discriminação que têm o efeito de marginalizar e de despotencializar um grupo de pessoas que com atributos específicos, promovendo a idéia de que são menos do que outros em sua sociedade. $\mathrm{O}$ ageism, ou preconceito de idade, caracteriza-se por um processo de marginalização em que as necessidades e os interesses dos idosos recebem menos atenção do que os das pessoas mais jovens. O preconceito de idade reflete-se como uma tendência geral de marginalizar pontos relativos aos velhos e como tendência de associar indevidamente a velhice a algo negativo, pejorativo, e não como uma fase da vida que tem aspectos positivos e negativos. Há uma percepção discriminatória expressa no meio social. Parece ser vergonhoso ser veIho em nossa cultura, visto que usamos tantos artifícios para esconder a idade, copiamos modas dos jovens e disfarçamos as marcas e sinais que 
nos aproximam da condição indesejada. Compreendendo a noção de estigma como um atributo que implica desvalorização, inferioridade e que coloca a pessoa em uma situação de desvantagem em relação às outras, foi que, neste estudo, tivemos como hipótese, entendida aqui como suspeita ou desconfiança (Moreira, 2004), que a vivência do envelhecimento é uma experiência estigmatizada.

\section{Método}

Este estudo consistiu em uma pesquisa qualitativa na qual foi utilizado o método fenomenológico crítico (Moreira, 2004) para coleta e análise de resultados. $O$ objetivo deste método é a busca do significado da experiência vivida para um sujeito que é compreendido como protagonista de sua própria experiência de lebenswelt (mundo vivido).

A "lente" utilizada para analisar e discutir os resultados foi a fenomenologia "mundana" de Merleau-Ponty (1908-1961), filósofo existencialista e fenomenólogo [francês] que articulou harmonicamente a fenomenologia e a existência. Para ele, a fenomenologia "é o estudo das essências, mas também uma filosofia que re-situa as essências dentro da existência e só compreende o homem e o mundo a partir de sua facticidade" (MerleauPonty, 1945/1996, p. 5), isto é, da própria existência concreta. Trata-se de uma filosofia para a qual o mundo já está lá antes de qualquer reflexão que se possa fazer sobre ele. Essa "lente" busca o significado da experiência vivida de uma forma eminentemente crítica ou "mundana" (Moreira, 2004), no sentido em que ela existe no mundo, entrelaça-se e se constitui mutuamente com ele. Assim, por mais que a experiência de envelhecer seja apreendida no campo individual, ela não pode ser pensada e compreendida fora do contexto no qual o sujeito está imerso [e entranhado]. Referenciar-se no pensamento de Merleau-Ponty significou um esforço para compreender o fenômeno do envelhecimento perpassado pelo mundo, dialogando com ele; e desse diálogo emergiram os sentidos que procuramos descobrir.

Buscamos, por meio da iniciativa de compreender a experiência subjetiva das pessoas no processo de envelhecimento em mútua constituição com a realidade sócio-cultural, investigar como as pessoas vivenciam o processo de envelhecimento na contemporaneidade ocidental, identificar as vinculações e influências sócio-culturais das diversas manifestações de sofrimento psíquico resultantes da vivência do envelhecimento no sujeito contemporâneo, e investigar o envelhecimento como experiência estigmatizada.

Empreendemos esse desafio com indagações, premissas, incertezas e convicções que já tínhamos. Partimos, então, da hipótese de que as pessoas sofrem ao se perceberem envelhecendo em virtude não só da apro- 
ximação com a questão da finitude, mas também devido ao estigma que o velho carrega na sociedade ocidental contemporânea. Como pesquisadores mundanos, que se entrelaçam e se implicam no mundo, vertente na qual pesquisador e objeto surgem como dimensões imbricadas, acreditamos que não se escolhe ingenuamente um fenômeno para estudar. Freqüentemente o pesquisador tem pistas, suspeitas, hipóteses sobre o que pretende pesquisar. A palavra hipótese, proveniente do grego hypóthesis e do latim hypothese, significa "suposição, conjetura, acontecimento incerto, eventualidade, suposição duvidosa, mas não improvável" (Ferreira, 1975, p. 728).

O pesquisador jamais será neutro, e, na medida em que faz parte do mundo, o constitui e é constituído por este, o conhece, este mundo lhe é familiar. Será justamente para romper esta familiaridade que ele utilizar-se-á da redução fenomenológica.... O pesquisador vive um atolamento no mundo que é congênito; ele não é um passarinho capaz de praticar um pensamento de sobrevôo, esquecendo este atolamento, o que tanto irritava Merleau-Ponty. (Moreira, 2004, p. 452)

Na tentativa de compreender a experiência vivida do envelhecimento em sua inter-relação com o mundo, optamos pela adoção de dois instrumentos de coleta de dados da experiência: entrevistas fenomenológicas e um trabalho de campo realizado em um contexto representativo da contemporaneidade, definido como uma clínica de estética. No trabalho de campo, foram empregados instrumentos oriundos tradicionalmente do método etnográfico, como a observação direta e a observação participante. Dado que a etnografia é um método que por excelência prioriza a análise cultural dos fenômenos, os registros do trabalho de campo puderam se somar ao estudo fenomenológico na busca de compreensão do lebenswelt (mundo vivido) dos sujeitos colaboradores.

Foram entrevistados quinze sujeitos colaboradores, os quais emergiram do campo de investigação: uma clínica de estética localizada em Fortaleza, que oferece serviços integrados de estética, saúde e medicina estética. Conversamos com 12 mulheres e 03 homens que se encontravam na fase de vida da maturidade (de 40 a 60 anos). A escolha desses sujeitos pressupôs a existência de uma mobilização maior para a questão do envelhecer, já que todos estavam fazendo tratamentos de rejuvenescimento. A observação participante foi realizada por meio de visitas semanais ao campo, ao longo de 8 meses, onde conversávamos informalmente com funcionários e clientes e registrávamos nossas observações em um diário.

Para tratar os dados obtidos, foram reproduzidos os passos sugeridos para uma análise fenomenológica segundo a formulação de Moreira (2004), a partir do modelo proposto por Giorgi (1985): as entrevistas foram transcritas literalmente, produzindo o texto nativo, que foi dividido em mo- 
vimentos e nomeado em categorias de significados emergentes. Os dados qualitativos obtidos através das observações no campo complementam a análise fenomenológica realizada sobre o fenômeno do envelhecimento, enriquecendo a compreensão dos significados dessa experiência, ao revelarem dimensões sócio-culturais que estão para além da experiência subjetiva, ao mesmo tempo em que a compõem.

\section{Os resultados}

O que se vive na experiência de envelhecer representa um posicionar-se subjetivo diante de possibilidades infinitas de um jogo de afirmação e negação desse processo, traduzindo-se numa vivência ambígua, dotada de múltiplos sentidos, o que se fundamenta na noção de múltiplos contornos, segundo a perspectiva de Merleau-Ponty (1966/1980), que defende a idéia de que não há definições, limites ou contornos únicos, mas múltiplas maneiras de um fenômeno se manifestar.

Sintetizamos os achados mais relevantes deste estudo, ilustrados com algumas falas dos colaboradores, os quais são apresentados com nomes fictícios. Os significados que emergiram da experiência de envelhecer na contemporaneidade revelam:

1.0 envelhecer despontou como uma experiência ambígua, dotada de múltiplos significados que podem revelar aspectos positivos, reconhecidos como ganhos ou aquisições existenciais, ou enfocar aspectos negativos, identificados como perdas, apreensões e sensações desconhecidas, que angustiam e geram mal-estar, ou, ainda, evidenciar contradições que aludem ao fenômeno como algo dicotomizado, em que o que acontece com o físico não encontra respaldo no psicológico, sendo algo inevitável e, ao mesmo tempo, muito temido e indesejado. Os depoimentos abaixo expressam tais sentidos.

Pra mim, envelhecer significa saber mais, é um ato de aprender mais, de se cuidar mais, de ter mais sabedoria. (Diva, 54 anos)

Mas envelhecer é...tem, pra mim, envelhecer é algo que amedronta, que não gosto de pensar... Acho a velhice triste. (Anita, 44 anos).

A ambigüidade da experiência de envelhecer se evidencia nas falas acima pela conjugação de aspectos positivos - envelhecer traz sabedoria - e negativos - envelhecer amedronta. Estudos anteriores encontraram múltiplos significados do envelhecer em diferentes culturas, indicando que não existe uma visão universal do processo de envelhecer (Adler, 1999; Beauvoir, 1990; Uchôa, 2003).

2. A ambigüidade do processo parece decorrer também da vivência do envelhecimento como uma transição que causa estranheza ao sujeito, 
uma experiência dicotomizada, caracterizada por uma dissonância entre o interior e o exterior da pessoa diante de um corpo que se transforma e uma mente que não acompanha essa transformação.

Quando eu falo no envelhecimento, eu falo apenas no caráter físico, porque no caráter, no que tange o... a você por dentro, a tua cabeça, a tua agilidade, as tuas coisas, o teu dia-a-dia, eu ainda não, não consigo me ver envelhecendo. Eu consigo me ver envelhecendo no espelho. (Paula, 46 anos)

Ao ol har pra frente... eu não consigo me ver velha, idosa, eu não consigo, realmente é chocante. É como se não fosse eu. Não combina, é estranho. (Ivana, 43 anos)

A ambigüidade aqui se dá dentro de uma visão dicotomizada, em que o"interior" do sujeito [colaborador], sua"alma",se sente jovem, enquanto o"exterior", seu corpo, está envelhecendo. Deixar de ter um corpo jovem e belo pela deterioração biológica natural passa a ser vivido com um sofrimento adicional diante da "estetização da vida cotidiana" (Feathersthone, 1995; Maia \& Albuquerque, 2000).

3. A meia-idade ou maturidade é experienciada como uma etapa da vida na qual as pessoas se sentem em uma transição, na qual não se é nem jovem nem velho; não se tem o vigor do corpo jovem, porém ainda não se vivem as restrições decorrentes da velhice. Nessa fase do ciclo vital, ocorre o despertar para o envelhecimento e os sujeitos vivenciam transformações de ordem física, psicológica e social que trazem uma diversidade de descobertas, novos conflitos existenciais, novas responsabilidades, novos cuidados e novos desafios impostos pela necessidade de se adaptar a tantas mudanças e se preparar para um futuro desconhecido.

O primeiro "senhora" que você recebe é estranho, é... essa sensação, então em outra hora, eu sou... eu faço parte de outro grupo. (Neila, 46 anos)

A gente já sente que está com algumas limitações, a gente já não pode mais fazer algumas coisas com a intensidade que se fazia. $A$ idade já começa a pesar, então a gente já começa a respeitar mais os limites. (Gerson, 49 anos)

Quando chegou a menopausa, eu achei que era assim: um ponto de definição, um marco da minha passagem para a maturidade. (Diva, 55 anos)

A transição do ser jovem para o ser velho é observada a partir de mudanças corporais, bem como de formas de tratamento sociais, nas quais os "limites" impostos pela idade se evidenciam, fazendo com que o sujeito [colaborador] entre em contato com essa fase de transição que o porá como parte do grupo de pessoas idosas (Costa, 1998; Minayo \& Coimbra Jr., 2002).

4. As reações à experiência do envelhecimento na maturidade contemplaram tanto a negação, como a resistência e a aceitação do processo. 
Envelhecer, pra mim, é viver um dia após o outro e aproveitar bastante o momento, eu não penso isso. Eu vivo o meu momento, eu vivo o meu presente.... Eu não penso no amanhã, que é pra não criar mais ruga ainda. Juro como eu não penso. Eu nunca paro pra pensar nisso, eu vivo o dia de hoje. (Hélio, 49 anos)

O que eu puder corrigir eu vou corrigir... eu vou preferir corrigir aos poucos e não me deixar totalmente vel ha pra fazer uma cirurgia e as pessoas perceberem visualmente que eu mudei, que eu rejuvenesci do dia pra noite.... Eu quero fazer intervenções progressivas pra que as pessoas me aceitem, pra que as pessoas não percebam que eu estou envelhecendo tanto. Porque o envelhecimento dói, né? (Anita, 44 anos)

Eu pensei que envelhecer fosse mais difícil, né? Há alguns anos atrás eu pensava que com 44 anos eu ia estar arrasada, mas não é isso que aconteceu. É difícil, mas quando eu era bem jovem era difícil também, então é o viver mesmo que é complexo, não é só a maturidade ou a velhice. Eu jamais poderia ter o que eu tenho hoje se eu não tivesse chegado a essa idade, então eu quero mais. (Flora, 44 anos)

Percebe-se que alguns sujeitos [colaboradores] parecem aceitar bem a velhice, outros resistem a ela, tentam negá-la ou "evitá-la". Reações diferentes ao processo de envelhecer mostram a singularidade de cada sujeito (Neri, 2001) diante da universalidade do processo.

5. A experiência de envelhecer suscita medos, temores e receios, os quais se expressam na forma de preocupações e apreensões com o futuro e com a velhice que se aproxima. Emergem o medo da solidão, da morte, de doenças, da dependência física e psíquica, de perder os espaços e papéis conquistados, dos conflitos intergeracionais, da redução do poder aquisitivo e da eventual piora das condições de vida no futuro.

Eu tenho medo assim, medo de ficar só, eu não queria ficar só. E eu acho que as pessoas velhas, a maioria fica só. (Flora, 44 anos)

A questão de depender dos outros, eu tenho medo... eu sempre fui muito autônoma, essa coisa de ficar... ter esse risco de depender, me dá uma certa angústia... (Neila, 46 anos)

só não gostaria de envelhecer porque eu não quero morrer, mas não tem outro jeito, outro caminho. (Maria, 52 anos)

As falas acima ilustram pontos que constituem a experiência de envelhecer como uma experiência estigmatizada, na qual o velho vivenciaria a solidão, a dependência, a proximidade da morte, todas estas consideradas experiências negativas, ou a evitar. Os entrevistados vivenciam o estigma, na medida em que se vêem diferente do previsto pela sociedade (Goffman, 1998; Lewis, 1998).

6. Confirma-se a percepção de uma concepção tradicional de velhice que associa velhice a declínio, doença, decadência e outros atributos estigmatizadores, embora os sujeitos colaboradores percebam mudanças 
no tratamento social reservado à velhice e aos velhos e constatem uma tendência de transformação dessa visão [tradicional].

A minha mãe dizia que tinha horror de ser chamada de velha, queria morrer antes que chamassem ela de velha, ela morreu com 53 anos.... mas uma velha realmente é uma coisa desprezível, porque... "sai, velho, daqui".. "velha chata"... "velha coroca". Geralmente o velho é associado a coisas decadentes, a palavra velho significa coisa decadente, eu não quero ser associada a isso jamais. (Beatriz, 54 anos)

Ave Maria, servelhoéum crime, principalmente porque há um preconceito terrivel contra a velhice...O velho é uma pessoa inativa, o velho é uma pessoa que não presta mais, velho não tem direitos, velho não é... não pode isso, não pode aquilo. (Anita, 44 anos)

A imagem da velhice é esta coisa triste, solitária, discriminada, que incomoda... (Maria, 52 anos)

As pessoas, ao envelhecer, começam a se tornar descartáveis. (Paula, 46 anos)

Agora estão começando a despertar pra o valor do idoso, porque o idoso também tem muita experiência pra passar. (Carlos, 54 anos).

De forma ainda mais explícita do que no item anterior, o estigma de envelhecer aparece nesses depoimentos, nos quais os sujeitos colaboradores falam em preconceito, em discriminação, em ser descartável, todos estes atributos que permeiam as sociedades contemporâneas (Goffman, 1998; Goldfarb, 1998, Tompson ,1999).

7. Os sujeitos colaboradores não se identificaram com o modelo de velhice tradicional, que é uma imagem estigmatizadora, e vislumbraram, para seu futuro, um modelo de velhice mais autônoma, ativa e bem-sucedi$\mathrm{da}$, com novos comportamentos e com estilo de vida mais identificado com a juventude. Coexistem as duas imagens:uma [tradicional] que vale para os outros e outra mais dinâmica, que é adotada para si próprio. Observamos a identificação dos colaboradores com um novo modelo de velhice cujo acesso não é universalizado, é restrito a classes sociais economicamente privilegiadas, a despeito de inaugurar a produção de novos sujeitos e novas subjetividades e contribuir para a quebra da reprodução da vivência estigmatizadora do envelhecimento.

Eu não quero entrar no envelhecimento convencional, de todo mundo, é ser aposentada, é... chazinho das cinco; eu posso tomar chá das cinco sem ser velha.... Quero envelhecersendo muito ativa, fazendo coisas que gosto, desfrutando, curtindo. Quero fazer muitas coisas, tocar meus novos planos depois da aposentadoria, trabalhar com o que gosto, viajar, curtir. (Eva, 50 anos)

Eu acho que, se você envelhecer com condição social, você é aceito em qualquer lugar, você consegue sobreviver. O problema é você envelhecer sem condição. Se você envelhecer sem dinheiro, você não consegue mais nada, você está perdido. Que além de você não ter quem cuide de você, você já não tem mais força pra trabalhar, você não tem aparência, você não tem nada. (Maria, 52 anos) 
É interessante observar como essas falas reconhecem um conceito tradicional de envelhecer como experiência negativa, mas supõem que ele pode ser "driblado"ou superado se a pessoa se mantiver ativa e remuneradamente produtiva - valores típicos de uma sociedade capitalista. Esses dados corroboram a percepção de Debert (2002) de que existe, na sociedade brasileira, uma tendência crescente de representar o velho [de forma não tradicional, isto é,] mais positivamente.

8. A pesquisa mostrou haver elementos que apontam para a compreensão da experiência de envelhecer como uma experiência estigmatizada. O estigma de ser velho ou estigma da idade apareceu nos discursos dos colaboradores de forma explícita ou implícita e nas diferentes formas de enfrentar esse processo, sendo manifestado em vivências individuais de exclusão, rejeição, inferiorização ou valorização da aparência e estética jovem em vários espaços: familiar, profissional e social. Boa parte dos problemas e sofrimentos vividos na experiência de envelhecer parece derivar da estigmatização e do preconceito existente em nossa cultura e sociedade, que não está preparada para acolher limitações, corpos imperfeitos e a finitude humana.

Sinto que a sociedade rejeita a pessoa quando é velha. Ser velho é ser rejeitado. Você vê dia a dia: o mundo é para os jovens, antes não era assim, mas hoje infelizmente é assim. Então, para você se tornar parte dessa sociedade, ativamente trabalhar, você precisa aparentar que não é tão velho como a gente é. (Carlos, 54 anos)

Eu sou síndica do edifício onde moro, e eu percebo que ninguém mais tem paciência com o velho e que sem querer o velho atrapalha... a maioria está falando sempre a mesma coisa,já anda devagar, não pode acompanhar os filhos, os netos num passeio ou numa viagem porque eles atrapalham, porque andam lentamente, repetem as mesmas coisas e isso é coisa que incomoda todas as pessoas. (Maria, 52 anos)

Mais uma vez as falas dos sujeitos colaboradores explicitam a vivência do estigma de envelhecer com sentimentos de rejeição e exclusão social, todos estes integrantes dos processos de estigmatização dos idosos, tal como indicam estudos anteriores (Gusmão, 2001; Zuben, 2001).

9. Os sujeitos colaboradores desenvolvem estratégias de enfrentamento direto e indireto do estigma de ser velho, que exclui, inferioriza e desvaloriza as pessoas, apoiado na intensa oferta de recursos e práticas científicas e nas imagens veiculadas na mídia, de uma velhice diferenciada.

Eu sinto que estou chegando na época de decadência, aí como eu costumo me adiantar aos fatos, então eu tento fazer alguma coisa. Logicamente não se pode fazer muito, o processo é inevitável. Mas se você pode alongar esse prazo, então tem que agir. (Carlos, 54 anos) 
Você vai descobrindo que você tá ficando velha, né? E daí começa a sentir a necessidade de procurar consertar determinadas coisas que você não gosta mais no teu físico. (Paula, 46 anos)

Os entrevistados enfrentam diretamente o estigma quando procuram transformar ou modificar o corpo que apresenta marcas e evidências do envelhecimento, tentando adiar ou evitar os efeitos da passagem do tempo ao se submeterem aos diversos tratamentos estéticos e passarem a ser consumidores de inúmeros produtos e recursos anti-envelhecimento que a ciência, como a medicina estética e a cosmetologia disponibilizam no mercado (Feathersthone, 1995; Maia \& Albuquerque, 2000).

10. O enfrentamento indireto parece acontecer quando eles buscam a adoção de estilos de vida, padrões, hábitos, comportamentos e costumes identificados com os "não velhos", isto é, os jovens e a juventude tão valorizada e enaltecida no contexto contemporâneo.

Adoro carnaval, adoro festa, adoro salto alto, eu gosto de ser diferente, ser jovem. (Luisa, 47 anos)

Eu vou ser sempre velh a com essa minha cabeça jovem. Eu gosto de estar no meio de jovens. Não que eu não me relacione com velhos... quando eu era jovem, eu até me dava com as pessoas mais velhas, mas gosto de estar com jovens, gosto de assistir programação jovem, gosto de praticar um esporte, eu sou muito ativa, gosto de balada. (Olga, 40 anos)

Comportamentos considerados jovens, tal como gostar de carnaval, de festa, de esportes, passam a ser adotados por esses sujeitos [colaboradores] como uma forma de evitar sentir-se estigmatizado (Goffman, 1998).

11. Questões de ordem política, econômica e social também se entrelaçam com as singularidades individuais, definindo a experiência subjetiva de envelhecer. É o caso da preocupação com a inexistência de políticas públicas e mecanismos adequados para lidar com a população que envelhece, a despeito de todos os impactos sociais e econômicos desse fenômeno, gerando receios [particulares] voltados para as condições de vida de cada um no futuro.

Se ele tiver condições de se manter assim, de poder pagar a sua academia, de poder ter o seu planozinho de saúde, ele vai ficar muito bem. Agora, se ele não tiver nada disso e depender de saúde pública, aí realmente fica difícil...., vai pra fila de INSS, do SUS né? É difícil. (Olga, 40 anos)

Esse tema emergente nas entrevistas fenomenológicas leva a refletir sobre os limites da responsabilidade individual e da pública sobre o processo de envelhecer, sendo que o público constitui o individual e vice-versa; 
ou seja, a experiência singular está entrelaçada a uma experiência coletiva. Essa fala chama atenção para o aspecto ideológico que coloca a velhice como uma questão individual, sendo que ela tem também um caráter político e econômico (Debert, 2004; Mercadante, 2003; Motta, 2000).

Além dos temas emergentes nas entrevistas fenomenológicas, tal como discutidos acima, a imersão no campo enriqueceu, complementou e ampliou a descoberta dos significados da experiência de envelhecer [através das entrevistas realizadas]. Esse contexto constitui um espaço representativo da cultura contemporânea, efetivamente marcada pela imposição de um padrão estético que se distancia da velhice. As observações participativas ali realizadas possibilitaram algumas descobertas, a saber:

1. Uma clínica especializada em beleza e estética constitui um lócus privilegiado, que acena com a possibilidade de obter um corpo jovem, belo e perfeito. A experiência de envelhecer se faz em meio a uma profusão de técnicas de manutenção corporal. Pessoas sentem-se seduzidas pelas inúmeras ofertas de produtos, serviços e pacotes de tratamentos que retardam ou ocultam o envelhecimento, o que contribui para reforçar [ideologicamente] o estigma da velhice e enfatizar o mito da juventude eterna.

2. São intensos os apelos e as estratégias utilizadas pela mídia para induzir o consumo, tornando as subjetividades contemporâneas bastante permeáveis aos ideais veiculados pela publicidade, fato apoiado na ciência e operacionalizado pelas clínicas de estética, espaços de reprodução dessa cultura narcísica.

3. Os clientes de meia-idade parecem ser grandes consumidores de técnicas e tratamentos de rejuvenescimento, embora a procura por tratamentos também ocorra em idades mais prematuras. As mulheres ainda têm sido o alvo preferencial da indústria da beleza e são as grandes consumidoras de tratamentos, produtos e serviços que lhes possibilitam viver o sonho de beleza e de eterna juventude. Os homens ainda são minoria numa clínica de estética, mas já se pode identificar uma movimentação para a adequação de instalações e serviços destinados ao atendimento da demanda crescente do público masculino.

4. Numa clínica de estética, evidencia-se o quanto a experiência de envelhecer pode equiparar-se ao enfrentamento de uma luta, cujas armas serão fornecidas pela ciência. $O$ discurso mercadológico se apóia no discurso científico para fomentar a crença de que o corpo é maleável e que o envelhecimento pode ser combatido ou retardado por meio de várias técnicas médicas e estéticas que proporcionam às pessoas uma variedade de tratamentos voltados para a aquisição de uma aparência mais jovem.

5. A aliança do conhecimento científico (ou pseudocientífico) com o mercado (clínicas) parece difundir a idéia de solução para o problema do inevitável envelhecimento. Induz-se a percepção de que todos podem manter-se jovens e belos diante de tantas ofertas, tantos recursos, tantas "facilidades" disponibilizadas, como se o ato de envelhecer fosse uma 
questão de escolha individual. O corpo jovem, belo e saudável não é mais um ideal e, sim, um bem a ser conquistado.

6. O apoio no discurso científico parece levar as pessoas a associarem os tratamentos estéticos com a idéia de cuidados com a saúde, de modo que elas se sentem à vontade para investir financeiramente nessa conquista, desvinculando esse investimento da idéia de futilidade e desperdício.

A adoção do método fenomenológico com base na filosofia de Merleau-Ponty (Moreira, 2004), enriquecido com as técnicas etnográficas aplicadas em uma clínica de estética, ampliou a descoberta dos significados da experiência de envelhecer, pois permitiu ver que esse contexto constitui, sem dúvida, um espaço privilegiado para a compreensão de uma contemporaneidade marcada pela imposição de um padrão estético que se distancia da velhice (Feathersthone, 1995; Maia \& Albuquerque, 2000), onde há sujeitos que vivenciam esse processo com toda a ambigüidade e as contradições que lhes são inerentes (Adler, 1999; Beauvoir, 1990; Uchôa, 2003).

Os resultados evidenciam o quanto a experiência de envelhecer se constitui [pelo mundo,] pela cultura, pela sociedade, pela realidade social de um dado país, e mesmo por uma cultura mais específica, como a cultivada atualmente em Fortaleza, no nordeste do Brasil,e ainda pelos elementos subjetivos, biológicos ou endógenos que se encontram em cada singularidade. A partir do que se vive nessa experiência de envelhecer, emergiram significados que articulam o sujeito e seu contexto, evidenciando [através da experiência subjetiva o] que ocorre na mútua constituição entre mundo e sujeito.

\section{Conclusão}

Nesta pesquisa qualitativa, de cunho fenomenológico, que buscou compreender os significados da experiência de envelhecer a partir de uma visão mundana, tal como definida por Merleau-Ponty, evidenciou-se a noção de que a vida humana contempla um mundo sensível, a história e a cultura. A experiência de envelhecer, foco deste estudo, é uma experiência vivida de forma ambígua, com seus aspectos negativos e positivos, embora os negativos pareçam sobressair-se, entrelaçados a valores sócio-culturais que preconizam o belo, o novo, o produtivo.

A experiência de envelhecer constitui-se, então, em uma busca por evitar ou adiar o "inevitável", a própria velhice, e se apresenta como uma vivência estigmatizada, reveladora de sentidos diversos em um contexto perpassado por valores segundo os quais ser velho é ser desvalorizado, diminuído e excluído. O envelhecer passa, portanto, a representar uma batalha contínua quanto à aceitação de si mesmo e do curso natural da existência humana, um fluxo em que o "inevitável" é experienciado como "indesejável". 
O estigma de envelhecer contribui para um mercado que se propõe a "evitar"o"indesejável,"vendendo a juventude tão desejada na contemporaneidade, como se fosse possível evitar o envelhecimento.

\title{
From the inevitable to the undesirable:The experience of the stigma of the aging process in the contemporary world
}

\begin{abstract}
This article discusses the aging process in the western contemporary world, based on a phenomenological research developed with collaborating subjects who are in the life stage of maturity. This work has followed the phenomenological method based on Merleau-Ponty. The results provide elements that point towards the understanding of aging as an ambiguous experience, conveying multiples senses; it translates at the same time the identification with a negative stereotype and the refusal to bear a mark that inferiorizes or excludes people: the stigma of been old. Getting old in an environment composed by the worship of youth and beauty, that imposes an aesthetic pattern as an ideal to be conquered by everyone, transforms this experience, which is an "inevitable" biological phenomenon, into a "undesirable" cultural phenomenon.
\end{abstract}

Keywords: Aging. Stigma. Phenomenology.

\section{De l'inévitable à l'indésirable: l'expérience de vieillir dans la réalité contemporaine}

Résumé: Cet article apporte une discussion autour du vieillissement dans la réalité contemporaine occidentale, basée sur une recherche phénoménologique réalisée avec des sujets qui vivent l'âge mûr. Les résultats fournissent des éléments indicatifs d'une compréhension du vieillissement en tant qu'expérience stigmatisante, identifiée à un stéréotype négatif et donc à un refus de tout témoignage de la maturité. Vieillir dans une société vouant un culte à la jeunesse et à la beauté, où s'impose un idéal esthétique que l'on doit obtenir à n'importe quel prix, devient une expérience de tension entre le phénomène biologique «inévitable» et un phénomène culturel où la vieillesse figure comme «indésirable».

Mots-clés: Vieillissement. Stigmatisation. Phénoménologie. 


\section{De lo inevitable a lo indeseable: la experiencia vivida del estigma de envejecer en la contemporaneidad}

Resumen: Este artículo discute el proceso de envejecimiento en la contemporaneidad occidental a partir de una investigación fenomenológica realizada con sujetos colaboradores que se encuentran en fase de madurez. Los resultados fornecen elementos que apuntan para la comprensión del envejecimiento como una experiencia ambigua, dotada de sentidos múltiples, y también estigmatizada en la medida en que se traduce en la identificación con un estereotipo negativo y en un rechazo a ser portador de una marca que interioriza o excluye personas: el estigma de ser viejo. Envejecer en un escenario marcado por el culto a la juventud y a la belleza, que impone un patrón estético como ideal a ser conquistado por todos, transforma esa experiencia que es un fenómeno biológico "inevitable" en un fenómeno cultural de la orden de lo "indeseable".

Palabras-clave: Envejecimiento. Estigma. Fenomenología.

\section{Referências}

Adler, E. (1999). Aspectos emocionais da aposentadoria. In R. P. Veras (Org.), Terceira idade: alternativas para uma sociedade em transição (pp. 143-148). Rio de Janeiro: Relume-Dumará.

Beauvoir, S. (1990). A velhice. Rio de Janeiro: Nova Fronteira.

Birman, J. (1999). Mal-estar na atualidade: a psicanálise e as novas formas de subjetivação. Rio de Janeiro: Civilização Brasileira.

Coelho Júnior, N. (1988). O visível e o invisível em psicoterapia: a filosofia de MerleauPonty penetrando a prática clínica. Dissertação de Mestrado, Pontifícia Universidade Católica de São Paulo, São Paulo.

Costa, E.M.S.(1998). Gerontodrama:avelhiceem cena:estudosclínicosepsicodramáticos sobre o envelhecimento e a terceira idade. São Paulo: Agora.

Debert, G. G. (2002). O idoso na mídia. Recuperado em 01 de novembro de 2004, de http://www.comciencia.br/reportagens/envelhecimento/env12.htm

Debert, G. G. (2004). A reinvenção da velhice: socialização e processos de reprivatização do envelhecimento. São Paulo: Edusp.

Featherstone, M. (1995). Cultura de consumo e pós-modernismo. São Paulo: Studio Nobel.

Ferreira, A. (1975). Novo dicionário da língua portuguesa. Rio de Janeiro: Nova Fronteira.

Giorgi, A. (1985). Sketch of a psychological phenomenological method. In A. Giorgi (Ed.), Phenomenology and psychology research (pp. 8-22). Pittsburg: Duquesne University Press. 
Goffman, I. (1998). Estigma: notas de uma identidade deteriorada (4a ed.). Rio de Janeiro: LTC.

Goldfarb, D. C. (1998). Corpo, tempo e envelhecimento. São Paulo: Casa do Psicólogo.

Gusmão, N. M. M. (2001). A maturidade e a velhice: um olhar antropológico. In A. L. Neri (Org.), Desenvolvimento e envelhecimento: perspectivas biológicas, sociológicas e psicológicas (pp. 113-139). Campinas, SP: Papirus.

Lewis, M. (1998). Shame and stigma. In P. Gilbert \& B. Andrews (Eds.), Shame: interpersonal behavior, psychopathology and culture (pp. 127-140). New York: Oxford University Press

Maia, M. S., \& Albuquerque, A. (2000). Get there now! Cultura contemporânea, imediatismo e desamparo. Pulsional Revista de Psicanálise, 13(132), 81-88.

Mercadante, E. (2003). Velhice: a identidade estigmatizada. Serviço Social e Sociedade, 24(75), 55-73.

Merleau-Ponty, M. (1980). A dúvida de Cézanne (Coleção Os Pensadores). São Paulo: Abril Cultural. (Trabalho original publicado em 1966. Título original: La Doute de Cézanne)

Merleau-Ponty, M. (1996). Fenomenologia da percepção. São Paulo: Martins Fontes. (Trabalho original publicado em 1945. Título original: Phénoménologie de la perception)

Minayo, M. C. S., \& Coimbra Jr. (2002). Entre a liberdade e a dependência: reflexões sobre o fenômeno social do envelhecimento. In M. C. S. Minayo \& Coimbra Jr. (Orgs.), Antropologia, saúde e envelhecimento (pp. 11-24). Rio de Janeiro: Fiocruz.

Moreira, V. (2002). Psicopatologia crítica (Parte II). In V. Moreira \&T.Sloan, Personalidade, ideologia e psicopatologia crítica (pp. 106-248). São Paulo: Escuta.

Moreira, V. (2004). O método fenomenológico de Merleau-Ponty como ferramenta crítica na pesquisa em psicopatologia. Psicologia: Reflexão e Critica, 17(3), 447456.

Moreira, V. (2005). Ecology in the multiple contours of psychopathology. Revista Latinoamericana de Psicopatologia Fundamental, 8(1), 54-63.

Moreira, V. (2007). De Carl Rogers a Merleau-Ponty: a pessoa mundana em psicoterapia. São Paulo: Annablume.

Motta, A. B. (2000). Chegando pra idade. In M. M. L. Barros (Org.), Velhice ou terceira idade? (pp. 223-235). Rio de Janeiro: Fundação Getúlio Vargas.

Neri, A.L.(2001). Ofruto dá sementes: processo de amadurecimento envelhecimento. In A. L. Neri (Org.), Maturidade e velhice: trajetórias individuais e sócio-culturais (pp. 11-52). Campinas, SP: Papirus.

Thompson, S., \& Thompson, N. (1999). Older people, crisis and loss. Illness, Crisis \& Loss, 7(2), 122-133.

Uchôa, E. (2003). Contribuições da antropologia para uma abordagem das questões relativas à saúde do idoso. Cadernos de Saúde Pública, 9(3), 849-853. Recuperado 
em 31 de outubro de 2004, da SciELO (Scientific Eletronic Library OnLine): http:// www.scielo.br

Zuben, N. A. Von. (2001). Envelhecimento: metamorforse de sentido sob o signo da finitude. In A. L. Neri (Org.), Maturidade e velhice: trajetórias individuais e sócioculturais (pp. 151-182). Campinas, SP: Papirus.

Virgínia Moreira, Docente da Universidade de Fortaleza - UNIFOR. Endereço para correspondência: Av. Washington Soares, 1321. Edson Queiroz, Fortaleza-CE. CEP: 60811-341. Endereço eletrônico: virginiamoreira@unifor.br

Fernanda Nícia Nunes Nogueira, Docente da Universidade de Fortaleza - UNIFOR. Endereço para correspondência: Av. Dom Luis, 500, sala 1217. Aldeota, Fortaleza-CE, 60.1705508-900.Endereço eletrônico:fnicia@secrel.com.br 
